\title{
Post-mortem changes in the physical meat quality characteristics of refrigerated impala M. longissimus dorsi
}

\author{
L.C. Hoffman \\ Department of Animal Sciences, University of Stellenbosch, Private Bag X1, Matieland 7601, South Africa
}

\begin{abstract}
The effect of aging the $M$. longissimus dorsi of 13 impala at $4^{\circ} \mathrm{C}$ over a ten-day period was investigated. Large variation between animals was observed for the percentages drip and cooking loss as well as for the CIELab colour $\left(\mathrm{L}^{*}, \mathrm{a}^{*}, \mathrm{~b}^{*}\right)$ values. No trend could be observed for these physical characteristics over time. Means for all traits correspond to that reported in the literature for this species. Similarly, the tenderness of the muscle varied between the animals. However, the tenderness (as measured by a Warner Bratzler shear apparatus) of the muscle generally improved with time. The quadratic equation $\mathrm{y}=-0.0817 \mathrm{x}^{2}+0.4468 \mathrm{x}+10.477$ best described $\left(\mathrm{R}^{2}=0.32\right)$ this improvement in tenderness. The implications of this result is that fresh game meat producers can de-bone carcasses after 24 hours post mortem and leave the primal cuts to age in vacuum bags in the chiller, thereby utilizing the available chiller space more efficiently.
\end{abstract}

Keywords: Game meat, tenderisation, physical characteristics, aging

\# Corresponding author. E-mail:Ich@sun.ac.za

\section{Introduction}

The utilization of game for meat production within South Africa is increasing rapidly (Hoffman, 2003). One of the species that has been identified as having potential for producing game meat on a sustainable basis is the impala (Aepyceros melampus) (Fairall, 1985; Hoffman, 2000a). The methodology of cropping this game species has been described previously (Lewis et al., 1997; Hoffman, 2000b; Kritzinger et al., 2003). Normally cropped animals are exsanguinated by cutting the throat in the field and the offal is either removed in the field or in the abattoir (Hoffman, 2003). Carcasses are then hung with the skin on in the chiller until processed. There is however, preponderance amongst the producers of fresh meat to hang carcasses with the skin on for a number of days together with other carcasses or cuts that have had the skin removed. The reason for this is to enhance the tenderness of the primal cuts, particularly those originating from the back and the buttocks. This practice obviously increases the risk for bacterial contamination from the hides to the meat of the fully dressed carcasses (Veary, 1991).

The fore quarters and belly of the impala are normally processed either into sausages, typically dry boerewors, or into value added products that do not require aging.

The use of chill storage to enhance the tenderness process by means of the activity of the natural enzymes (calpains, cathepsins, protosomes, etc) has long been recognized and has been well documented for the traditional farmed species (see for example Dransfield, 1994 and Koohmaraie et al., 2003). This process can either be conducted by hanging the whole carcass for a number of days in the chiller or by removing the primal cuts and after vacuum packaging these, leaving them to age in a chiller. The latter is the route normally followed for species such as ostrich. However, very little data on the effect of aging on the enhancement of tenderness has been documented for the southern African wild ungulates. The effect of aging vacuum-packed impala $M$. longissimus dorsi on the physical characteristics of the muscle is thus reported.

\section{Material and Methods}

M. longissimus dorsi from 13 impala were sourced from a commercial abattoir. The effect of aging the muscles in a vacuum bag at $2.8{ }^{\circ} \mathrm{C}$ over a 10-day period on their physical characteristics was determined. All carcasses had hung for two days in a cooler at $2.8^{\circ} \mathrm{C}$ prior to the removal of the muscle. After the whole (left hand side) muscle had been removed, the muscles were individually vacuum packed and stored in the same cooler until required for the physical measurements. Every two days, three $\pm 1.2 \mathrm{~cm}$ thick muscle subsamples (the first sample taken in the lumbar region and each consecutive sample, caudally adjacent to it) cut perpendicular to the longitudinal axis of the muscle were taken for determination of colour, drip loss and cooking loss and toughness values. The colour of the M. longissimus dorsi was evaluated using a Color- 
guide $45^{\circ} 0^{\circ}$ colorimeter (Cat no: 6805 ; BYK-Gardner, USA) to determine $\mathrm{L}^{*}$, $\mathrm{a}^{*}$ and $\mathrm{b}^{*}$ values (Stevenson et al., 1989) with $\mathrm{L}^{*}$ indicating brightness, $\mathrm{a}^{*}$ the red-green range and $\mathrm{b}^{*}$ the blue-yellow range. Drip loss was expressed as the percentage moisture loss relative to the weight of the fresh sample after a $24 \mathrm{hr}$ hanging period in the cooler $\left(2.8{ }^{\circ} \mathrm{C}\right)$. Cooking loss (\%) was determined by placing weighed samples of approximately $50-70 \mathrm{~g}$, sealed in plastic bags, in water at $75{ }^{\circ} \mathrm{C}$ for $60 \mathrm{~min}$. The bagged samples were allowed to cool down in running water to $\pm 25^{\circ} \mathrm{C}$. Weight of the dried cooked samples were determined after decanting the liquid phase, and the cooking loss calculated as total fluid lost, expressed as a percentage of the fresh (uncooked) sample (Honikel, 1998). Thereafter, five $1.27 \mathrm{~cm}$ diameter samples (from the centre of each M. longissimus dorsi sample) were randomly removed for the determination of Warner-Bratzler shear force values (Voisey, 1976). The Warner-Bratzler head was attached to a Bongshin loadcell connected to a Masskot electronic scale. The samples were cut (at a cross head speed of $229 \mathrm{~mm} / \mathrm{min}$ ) parallel to the muscle fibre direction in order to measure the influence of the myofibrillar proteins. Maximum shear force values $(\mathrm{kg} / 1.27 \mathrm{~cm}$ diameter) were recorded for each sample (replicated five times) and a mean was calculated for each individual animal on each occasion.

Data were statistically analyzed for the effect of aging period using Proc GLM and Proc NLIN (SAS, 2000).

\section{Results and Discussion}

Similar to other red meat species, the $M$. longissimus dorsi of the impala showed variation for the various physical parameters between animals (Table 1). Coefficients of variation exceeded $20 \%$ for shear force and drip loss. Corresponding values were below $10 \%$ for the $\mathrm{L}^{*}$ and $\mathrm{a}^{*}$ colour values as well as cooking loss. Nevertheless, the mean values obtained for the physical parameters are similar to those reported in previous investigations on this species (Hoffman, 2000b; Kritzinger et al., 2003). With the exception of shear force, no conclusive trends over time were found for the various physical characteristics measured. Shear force decreased with time for all the animals (Figure 1). Of the various regression equations fitted, the quadratic equation $y=-0.0817 x^{2}+0.4468 x+10.477$ gave the best fit $\left(R^{2}=0.32\right)$.

Table 1 Descriptive statistics for the physical characteristics of thirteen impala $(\mathrm{n}=65)$ M. longissimus dorsi aged over a ten day period

\begin{tabular}{lccccc}
\hline Variable & Mean & s.d. & Maximum & Minimum & Variance \\
\hline Shear force $(\mathrm{kg} / 1.27 \mathrm{~cm} \varnothing)$ & 9.56 & 2.85 & 15.88 & 3.62 & 8.1490 \\
$\mathrm{~L}^{*}$ & 32.87 & 2.57 & 39.96 & 29.10 & 6.6216 \\
$\mathrm{a}^{*}$ & 11.22 & 1.11 & 13.73 & 9.16 & 1.2344 \\
$\mathrm{~b}^{*}$ & 7.81 & 1.25 & 11.23 & 4.68 & 1.5595 \\
\% cook loss & 29.18 & 1.71 & 34.18 & 24.71 & 2.9192 \\
\% drip loss & 2.72 & 0.83 & 5.30 & 1.44 & 0.6836 \\
\hline
\end{tabular}

\section{Conclusion}

The results clearly indicate that removing impala $M$. longissimus dorsi 48 hrs post mortem and vacuum packaging the muscles and then leaving them to age naturally in a chiller will enhance the tenderness of the muscle. If producers of fresh game meat were to follow this procedure, they would have a more efficient utilization of chiller space as well as the capability to process the lower value cuts more rapidly. An added advantage would be that microbial cross contamination between carcass hides and meat would be minimized.

\section{Acknowledgments}

The technical assistance of G. Herold and G.F. Jordaan is acknowledged with appreciation.

\section{References}

Dransfield, E., 1994. Optimisation of tenderization, ageing and tenderness. Meat Sci. 36, 105-121.

Fairall, N., 1985. Manipulation of age and sex ratios to optimize production from impala Aepyceros melampus populations. S. Afr. J. Wildl. Res. 15, 85-88. 
Hoffman, L.C., 2000a. The yield and carcass chemical composition of impala (Aepyceros melampus), a southern African antelope species. J. Sci. Food Agric. 80, 752-756.

Hoffman, L.C., 2000b. Meat quality attributes of night cropped impala (Aepyceros melampus). S. Afr. J. Anim. Sci. 30, 133-137.

Hoffman, L.C., 2003. Can South Africa produce game meat according to European Union standards? The Springbok and Impala story. In: Proc. $11^{\text {th }}$ Int. Meat Symposium on Consistency of Quality, January 2003. Irene, South Africa. pp. 257-268.

Honikel, K.O., 1998. Reference methods for the assessment of physical characteristics of meat. Meat Sci. 49, 447-457.

Koohmaraie, M., Veiseth, E., Kent, M.P., Shackleford, S.D. \& Wheeler, T.L., 2003. Understanding and managing variation in tenderness. In: Proc. $11^{\text {th }}$ Int. Meat Symposium on Consistency of Quality, January 2003. Irene, South Africa. pp. 3-13.

Kritzinger, B., Hoffman, L.C. \& Ferreria, A.V., 2003. A comparison between the effects of two cropping methods on the meat quality of impala (Aepyceros melampus). S. Afr. J. Anim. Sci. 33, 233-241.

Lewis, A.R., Pinchin, A.M. \& Kestin, S.C., 1997. Welfare implications of the night shooting of wild Impala (Aepyceros melampus). Anim. Welf. 6,123-131.

SAS, 2000. SAS for windows, Release 8.02 ed. SAS Institute Inc., Cary, NC, USA.

Stevenson, J.M., Seman, D.L., Weatherall, I.L. \& Littlejohn, R.P. 1989. Evaluation of venison color by an objective method using CIELab values. J. Food Sci. 54, 1661-1662.

Veary, C.M., 1991. The effect of three slaughter methods and ambient temperature on the $\mathrm{pH}$ and temperatures in springbok (Antidorcas marsupialis) meat. M.Med. Vet.(Hyg.) thesis. Faculty of Veterinary Sci., University of Pretoria, South Africa.

Voisey, P.W., 1976. Engineering assessment and critique of instruments used for meat tenderness evaluation. J. Text. Stud. 7, 11-48.

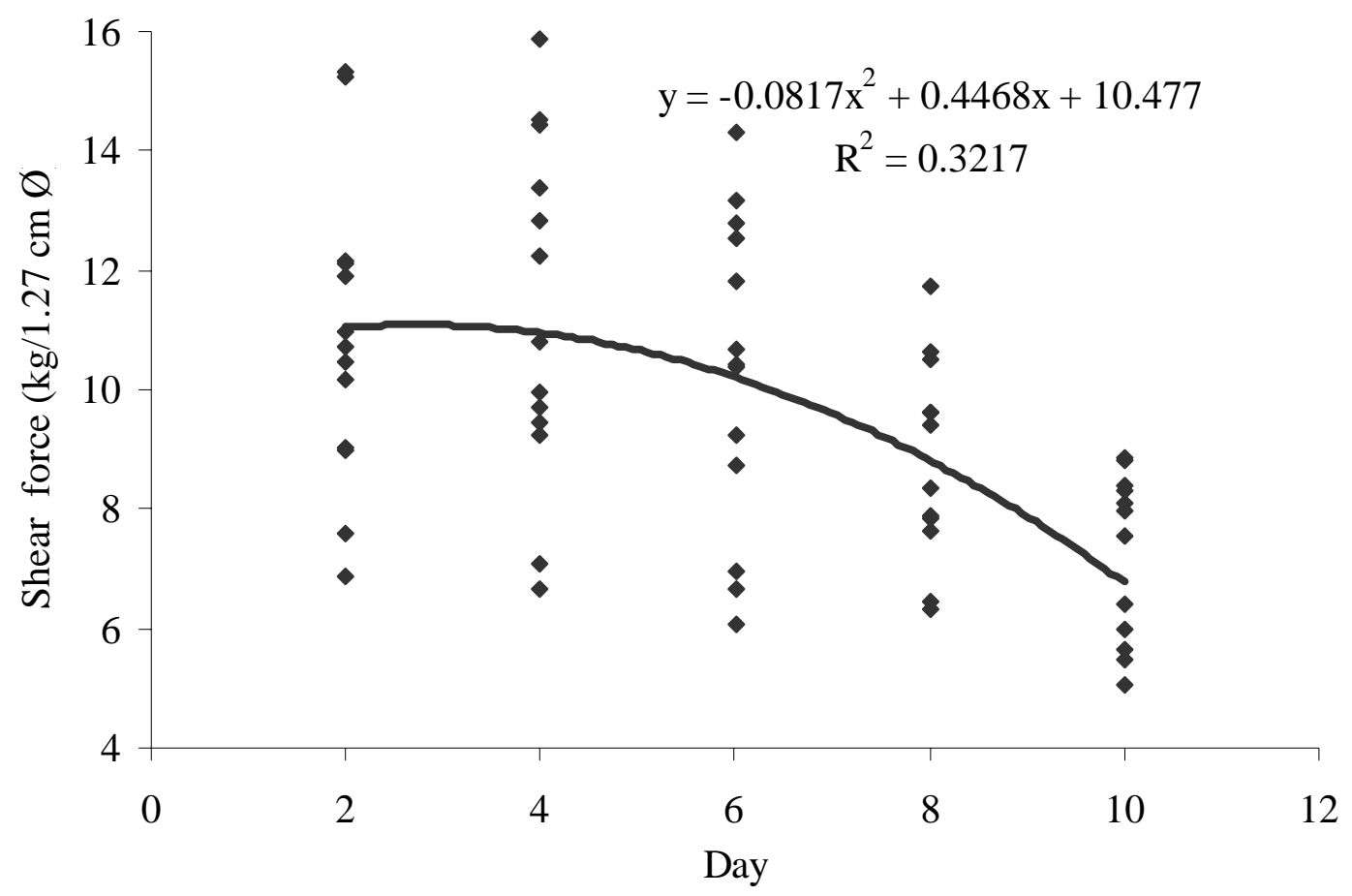

Figure 1 The general improvement in tenderness of impala $M$ longissimus dorsi aged over a 10-day period 